\title{
Dynamic simulation modelling of agricultural tractors with automatic deployment of ROPS
}

\author{
B. Martin-Gorriz¹, D. Ojados Gonzalez ${ }^{2}$, I. Ibarra Berrocal ${ }^{2}$, B. Miguel Hernandez ${ }^{3}$, G. Adolfo \\ Salcedo $^{2}$, A. Guasp Alburquerque ${ }^{2}$, A. Macian Morales ${ }^{2}$ \\ ${ }^{1}$ Universidad Politécnica de Cartagena. Dpto. Ingeniería de Alimentos y del Equipamiento Agrícola. \\ Paseo Alfonso XIII, 48, 30203, Cartagena. Spain. \\ ${ }^{2}$ Universidad Politécnica de Cartagena. Servicio de Apoyo a la Investigación Tecnológica. \\ Plaza del Hospital s/n, 30202, Cartagena. Spain. \\ ${ }^{3}$ Universidad Politécnica de Cartagena. Dpto. Ingeniería Química y Ambiental. \\ Paseo Alfonso XIII, 52, 30203, Cartagena. Spain. \\ Written for presentation at the \\ 2016 ASABE Annual International Meeting \\ Sponsored by ASABE \\ Orlando, Florida \\ July 17-20, 2016
}

\begin{abstract}
Tractor overturns are the leading cause of fatalities in the agricultural industry. An inadequate use of the deployable ROPS in agricultural tractors contributes to causing accidents. To help resolve this problem, an automatically deployable ROPS was designed, constructed and tested to be used for agricultural tractors with a front-mounted ROPS. Computer-based dynamic simulation modeling techniques, validated by practical rollover trials, were employed to investigate tractor lateral rollover behavior, with particular respect to the automatic deployment devices of protective structures for tractors with a front-mounted ROPS. The simulation model developed for this investigation was produced using SolidWorks $3 D$ software in combination with SolidWorks Motion dynamic simulation software, and for motion analysis ADAMS has been used as the calculation engine. The virtual scenarios always comprised two elements: tractor and ramp. A 1:16 scale tractor (New Holland T6070) has been modelled as the vehicle that is moved along the ramp. The tractor was equipped with the safety device for the automatic deployment of a ROPS, developed by the research team of the project. A spiral ramp was selected as the most appropriate method to obtain the rollover of the tractor. For validation by real rollover trials with the scale tractor, a real scale ramp (1:16) was built in acrylonitrile butadiene styrene using a $3 D$ printer, and the scale remote-control tractor was propelled along the ramp to the point of rollover. A high speed camera was used to determine the time and point of rollover. The results showed that the simulation scenarios of overturning have allowed us to obtain the values of the lateral slope angle of the tractor at each time, speed, and force by each of the wheels on the ramp and angular velocity of the tractor. Through real rollover trials with a scale tractor on a spiral ramp it has been possible to validate a simulated scenario. The simulation has shown good accuracy in the prediction of the roll angle; the maximum relative error between the simulated result and experimental data was $-3.01 \%$.
\end{abstract}

Keywords. tractors, ROPS, safety, passive safety, dynamic simulation.

\footnotetext{
The authors are solely responsible for the content of this meeting presentation. The presentation does not necessarily reflect the official position of the American Society of Agricultural and Biological Engineers (ASABE), and its printing and distribution does not constitute an endorsement of views which may be expressed. Meeting presentations are not subject to the formal peer review process by ASABE editorial committees; therefore, they are not to be presented as refereed publications. Citation of this work should state that it is from an ASABE meeting paper. EXAMPLE: Author's Last Name, Initials. 2016. Title of presentation. ASABE Paper No. ---. St. Joseph, MI.: ASABE. For information about securing permission to reprint or reproduce a meeting presentation, please contact ASABE at http://www.asabe.org/copyright (2950 Niles Road, St. Joseph, MI 49085-9659 USA).
} 


\section{Introduction}

Tractor overturns are the leading cause of fatalities in the agricultural industry. In the EU, a survey carried out by the EC commission of EC member states revealed that $40 \%$ of serious injuries and deaths during tractor overturns occurred when a foldable Roll Over Protection Structure (ROPS) was not deployed into its protective position (Hoy, 2009). An inadequate use of the deployable ROPS in agricultural tractors contributes to causing accidents. In the Region of Murcia (Spain), over the 2005-2012 period, in 11 of the 44 accidents with tractors, the ROPS was down at the time when the accident occurred, and this contributed to fatal accidents (Martin-Gorriz et al., 2012). To help resolve this problem, an automatically deployable ROPS was designed, constructed and tested to be used for agricultural tractors with a frontmounted ROPS (Ojados Gonzalez et al., 2016).

Computer-based dynamic simulation modeling techniques, validated by practical roll-over trials, have been employed to investigate small vehicle lateral rollover behaviour (Scarlett et al., 2006; Wang et al., 2009) and narrow tractors (Song et al., 1989; Silleli et al., 2007) with particular respect to the onset of vehicle lateral instability and the energy levels likely to be absorbed by the vehicle ROPS during the overturn event. When a dynamic simulation model is developed, the accuracy of prediction should be measured to establish a level of confidence in the model. Verification can be made by comparing model predictions to full-scale experimental results under identical operating conditions. The complexity and expense of full-scale experiments encourages the utilization of alternative methods such as physical scale-models. This methodology has been used previously by other researchers. Song et al. (1989) verified the simulation results of a powered model wheel-tractor on soft ground with experimental tests using a 3/8 scale battery-powered model tractor with radio-controlled speed and steering.

\section{Objective}

The present research sought to validate, using computer-based dynamic simulation modelling techniques, the rollover trials of an automatically deployable ROPS constructed for agricultural tractors built previously by the same authors (Ojados Gonzalez et al., 2016). Computer-based dynamic simulation modelling techniques, validated by practical rollover trials, were employed to investigate tractor lateral rollover behavior, with particular respect to the automatic deployment devices of protective structures for tractors with a front-mounted ROPS. It has been of particular interest to develop simulations that have allowed us to obtain dynamic data to analyze the conditions leading to rollover and the influence of the safety systems in the rollover, as well as studying the effectiveness of these systems as a measure of driver protection.

\section{Materials and methods}

\subsection{Dynamic simulation modelling of scale tractor in lateral rollover}

One of the most powerful methods for the study of tractor dynamics and stability is computer simulation. Computer simulation is particularly useful in predicting how a tractor will respond to external disturbances and given terrain conditions. It is also regarded as the best method for the analysis of the influence of tractor parameters on safety and performance (Kim and Rehkugler, 1987).

The simulation model developed for this investigation was produced using SolidWorks 3D modeller software in combination with SolidWorks Motion dynamic simulation software, and for motion analysis ADAMS has been used as the calculation engine. SolidWorks has been used as a design software. In our project this software has been used to: (1) model the pieces; (2) assemble the pieces; (3) parameterization of pieces and assemblies; (4) render images and animations (including simulations); and (5) obtain the physical properties of parts and assemblies (mass, centre of gravity location and moment of inertia), as well as the modification of these properties according to the needs of the user. SolidWorks Motion is a rigid body analysis tool; it interprets each mechanical part or sub-assembly produced in the SolidWorks modeller as a rigid body. ADAMS is a dynamic and cinematic analysis software used to investigate vehicle stability, which is particularly useful for this project. The calculation engine of ADAMS can analyze the complex behavior of assemblies, mechanics, performing precise calculations of forces, moments, forces of contact, etc.

The model was built up by specifying constraints between parts that describe how they can move relative to each other. Forces, motions or centre of gravity can then be introduced to drive the model. Next, the calculation of the movement has been executed and finally the animation of the simulation has been obtained. As results, graphics and data of the simulation have been obtained, regarding: (1) location; (2) linear and angular velocity; (3) linear and angular acceleration; and (4) contact forces. All this makes it possible to recreate a scenario in which the tractor will be seen in motion in various situations until the point of rollover.

The virtual scenarios always comprised two elements, ramp and tractor. A spiral ramp was selected as the most 
appropriate method to obtain the rollover of the tractor. The ramp was modelled so that there is an increase of slope of one degree per metre of advance of the tractor. For the model full-size real tractor the length of the ramp was $60 \mathrm{~m}$ and a final angle of 60 degrees whilst for the scale tractor the ramp was modelled at the same scale (Fig. 1). In all simulation scenarios the real tractor was positioned at the low-slope end of the roll-over ramp, and was propelled along the ramp to the point of rollover. The tractor model was positioned at the low-slope end of the roll-over ramp, and propelled along the ramp to the point of rollover.

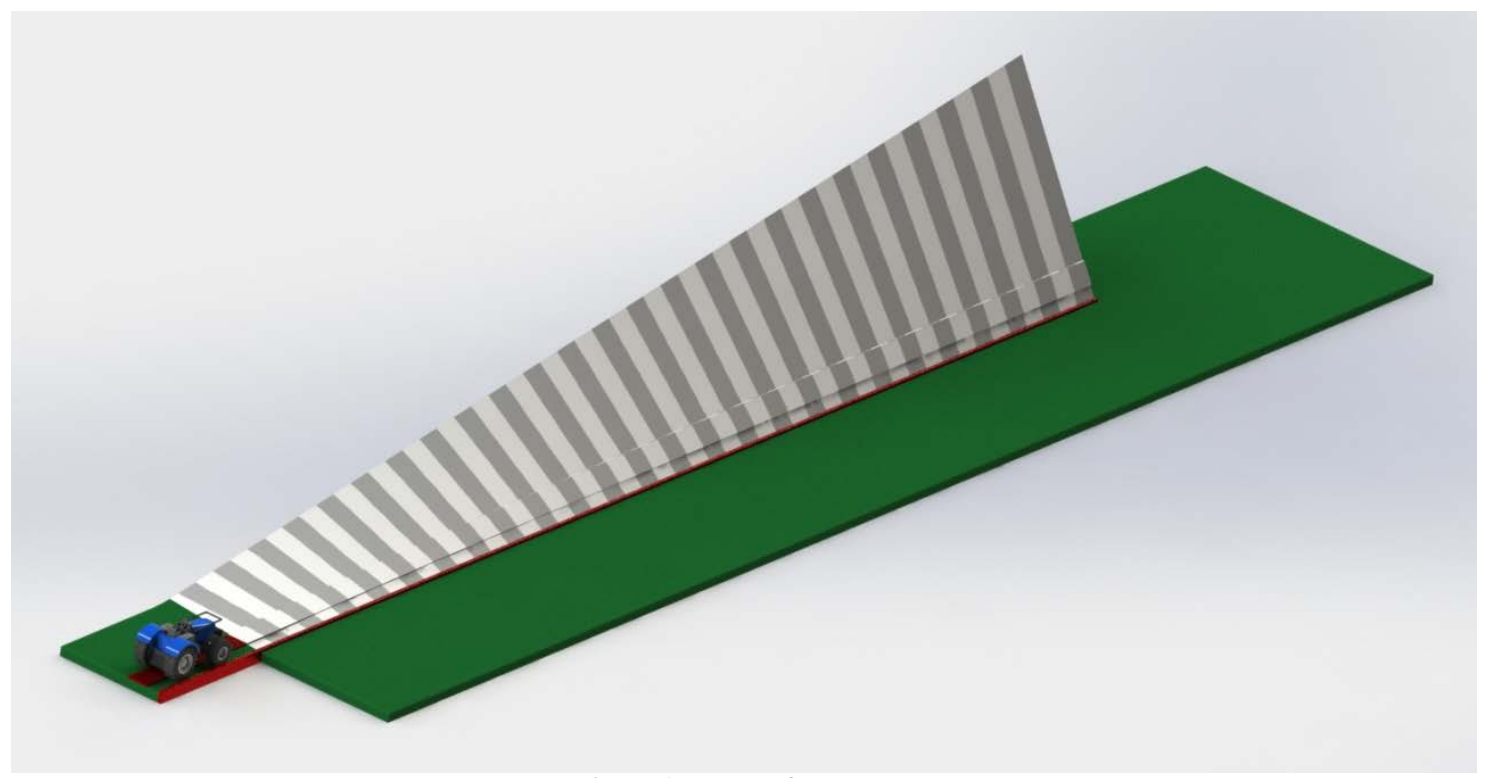

Figure 1. Model of ramp.

A scale tractor (1:16) was modelled as the vehicle that is moved along the ramp The tractor (New Holland, T6070) was equipped with the safety device for the automatic deployment of a ROPS (Fig. 2), developed by the research team of the project (Ojados Gonzalez et al., 2016). The use of dynamic simulation modeling has allowed to analyze the risk of rollover situations without having to carry out a real test of rollover with a tractor. This allows cost savings and avoids the risk of accidents by the driver.
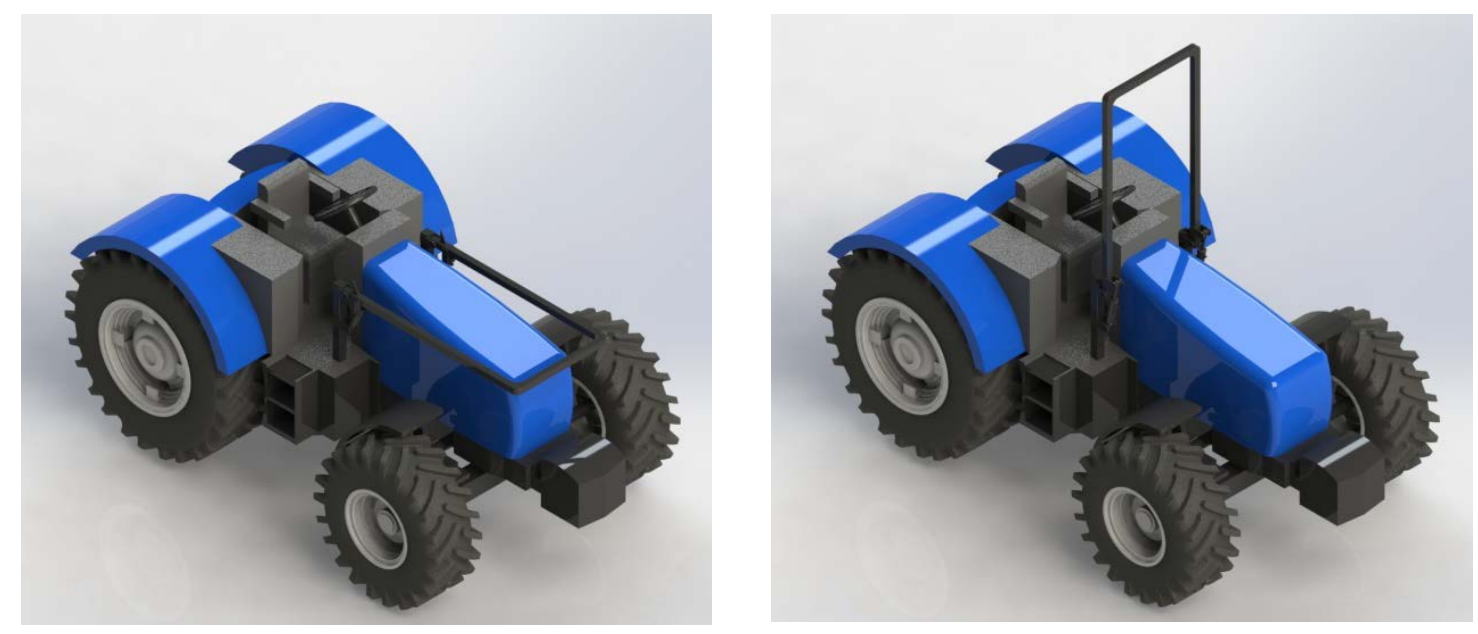

Figure 2. Model tractor with ROPS. (a) ROPS in retracted position, (b) ROPS in deployed position.

The simulation scenarios of rollover through the tractor modeling with the possibility to be modified have allowed the study of different situations. It has therefore been possible to analyze the influence of dimensional parameters of the tractor and the influence of the use and automatic activation of the ROPS at different speeds.

The simulation scenarios of the tractor were made at four different speeds $(23.44,30.01$ and $40.40 \mathrm{Km} / \mathrm{h}$ ) and with the ROPS in automatic deployment. In all simulation scenarios two criteria were taken to denote the start of the rollover: (1) the time in which the force in the left front wheel was becoming zero and therefore it was already not remaining in contact with the ground surface (Fig. 1), and (2) looking at the animation of the simulation frame by frame until there was a separation between the wheel and the ground surface. In order to compare the dynamic simulation model with the rollover 
experimental result a tire-surface friction coefficient of $\mu=1$ has been used.

\subsection{Validation of rollover dynamic simulation model}

For validation by real rollover trials with the scale tractor, a real scale ramp (1:16) was built in acrylonitrile butadiene styrene using a 3D printer (Fig.3), and the scale (1:16) remote-control tractor (Fig. 4) was propelled along the ramp to the point of rollover (Fig. 5). The scale tractor was implemented with electronic control system to automatically deploy the ROPS depending on the stability index (pitch angle and roll angle) when the tractor is near to the point of rollover (Ojados Gonzalez et al., 2016).

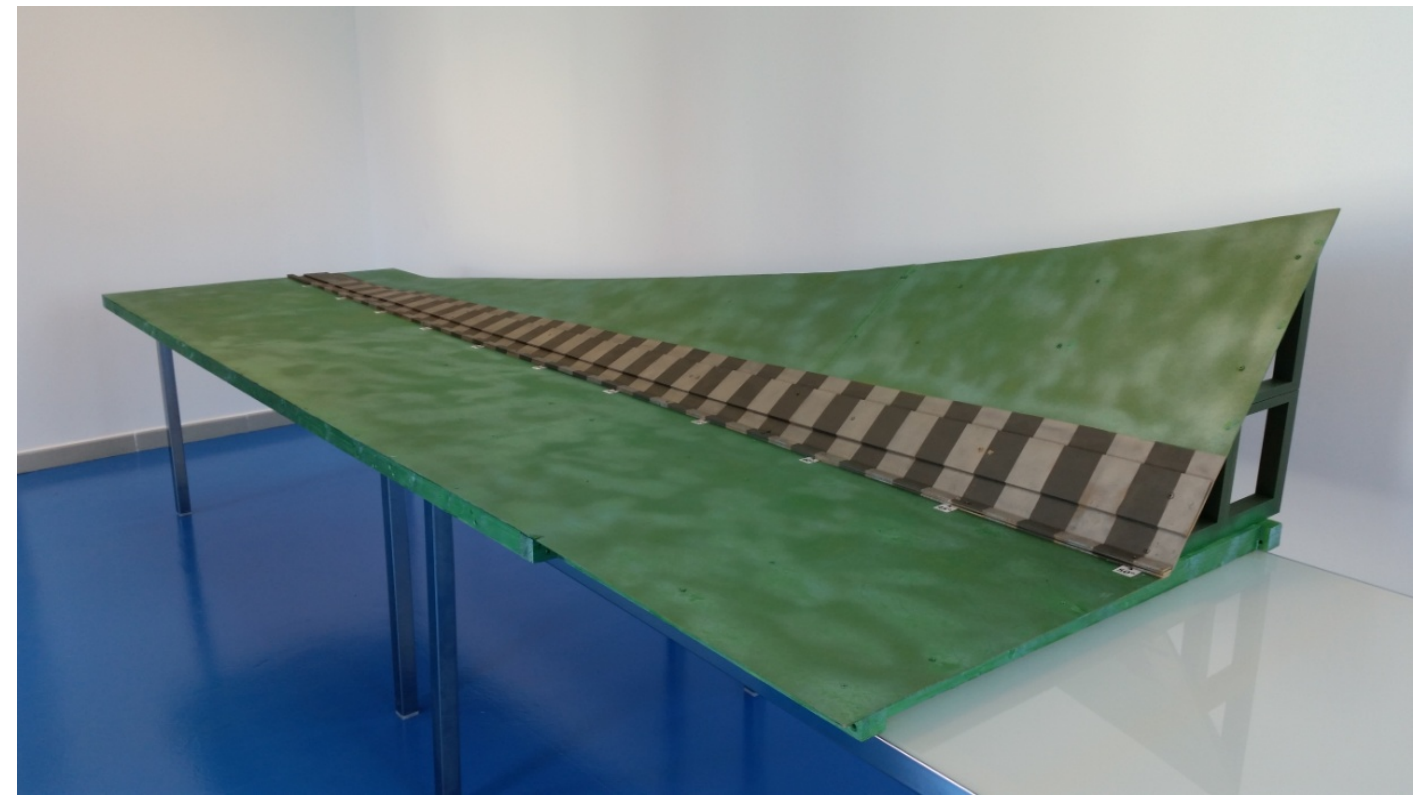

Figure 3. Image of the real ramp.

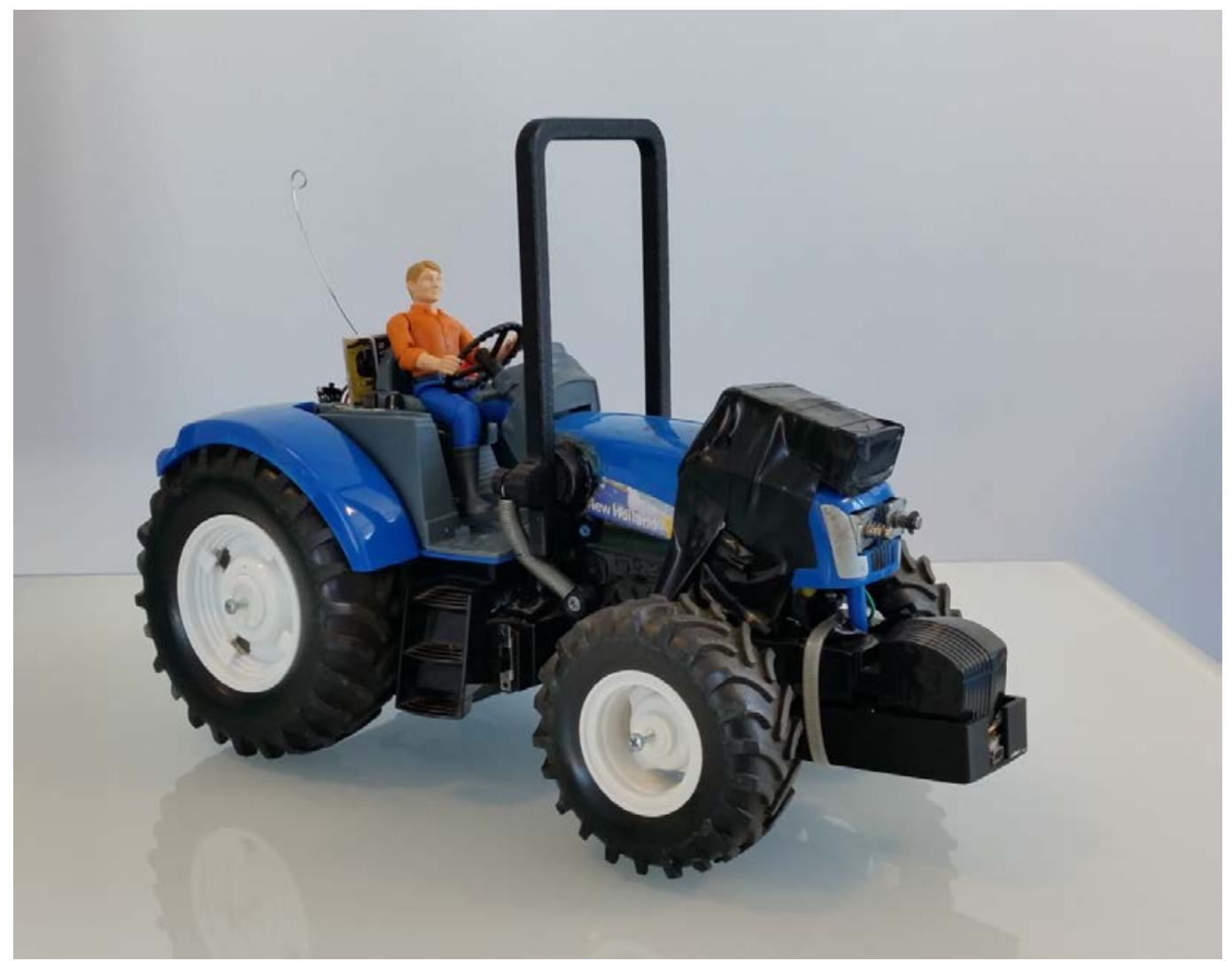

Figure 4. Scale (1:16) remote-control tractor. 


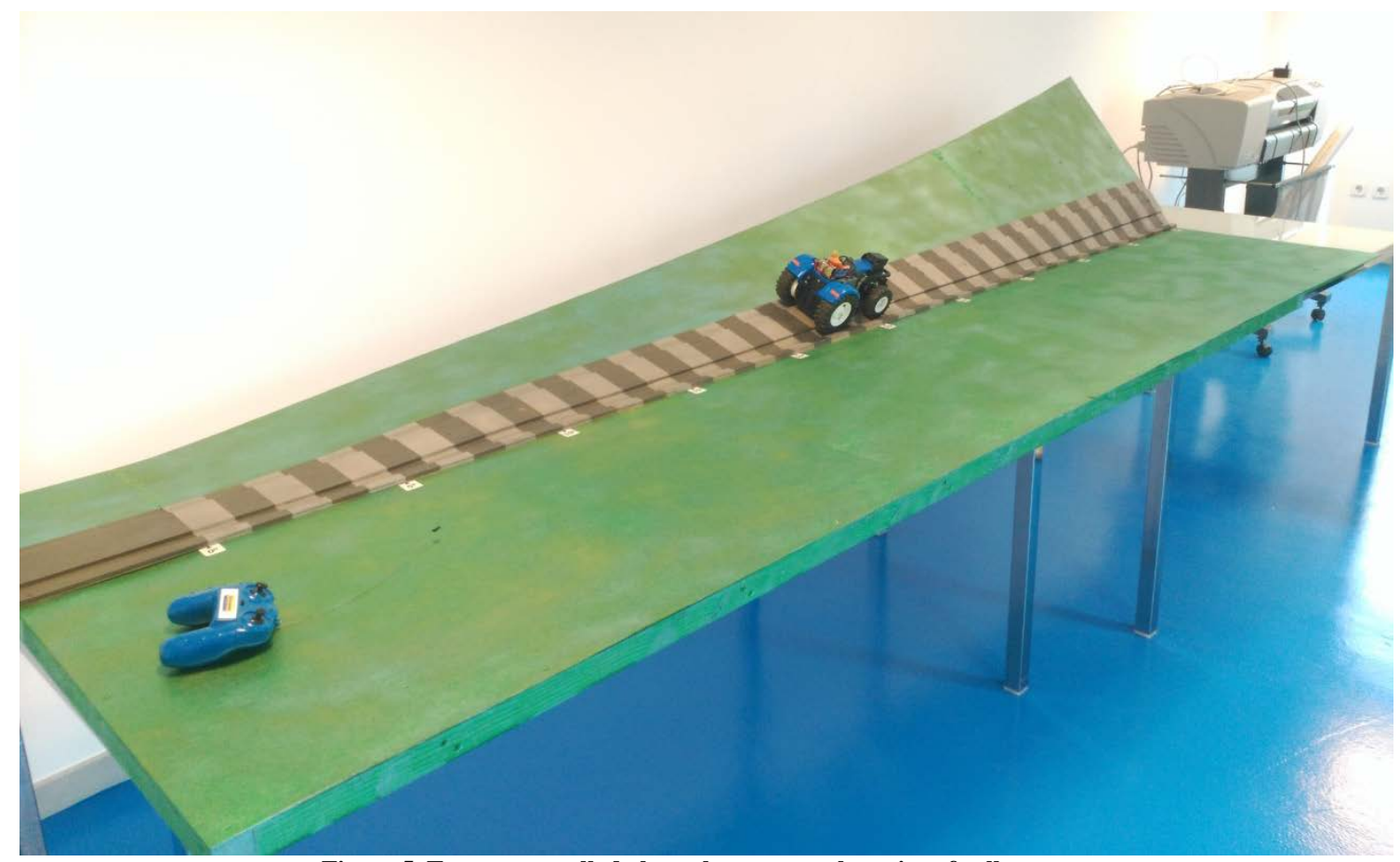

Figure 5. Tractor propelled along the ramp to the point of rollover.

A high speed camera (Faster Imaging Trouble Shooter TSHRMS, Artisan Technology Group, Champaign, IL, USA) was used to determine the time and point of rollover. The simulation scenarios of overturning have allowed us to obtain the values of the lateral slope angle of the tractor at each time, speed, and force by each of the wheels on the ramp and angular velocity of the tractor. These data have been used to calculate the overturn of tractor and compare it with the actual values when overturn takes place.

\section{Results and discussion}

\subsection{Rollover simulation model results}

The results of lateral rollover simulation at $23.44 \mathrm{~km} / \mathrm{h}, 29.62 \mathrm{~km} / \mathrm{h}$ and $39.47 \mathrm{~km} / \mathrm{h}$ are shown in Table 1 . Speed is a factor that increases the risk of rollover. High speed makes rollover occur with a lower slope and therefore increases the risk of it happening. In the simulation around $40 \mathrm{~km} / \mathrm{h}$ the slope on which the rollover occurred was 2 degrees less than that of the simulation at $23.44 \mathrm{~km} / \mathrm{h}$.

Table 1. Results of lateral rollover simulation.

\begin{tabular}{lccc}
\hline \multirow{2}{*}{ Items } & \multicolumn{3}{c}{ Test } \\
\cline { 2 - 4 } & A & B & C \\
\hline Speed of scale tractor 1:16 (km/h) & 1.46 & 1.88 & 2.53 \\
Real speed (km/h) & 23.44 & 29.62 & 39.47 \\
Starting angle of rollover (degrees) & 45.00 & 44.50 & 43.0 \\
Rollover time (s) & 0.40 & 0.40 & 0.60 \\
\hline
\end{tabular}

Fig. 5 and Fig. 6 show the last frame of the simulation scenario of overturning with ROPS down and deployed, respectively. The importance the ROPS has in saving the tractor driver has been highlighted. When the ROPS was down the tractor overturned more than 90 degrees (Fig. 5), which would surely in a real situation lead to the death of the driver. However, when the ROPS was deployed, the tractor overturned no more than 90 degrees (Fig. 6). 


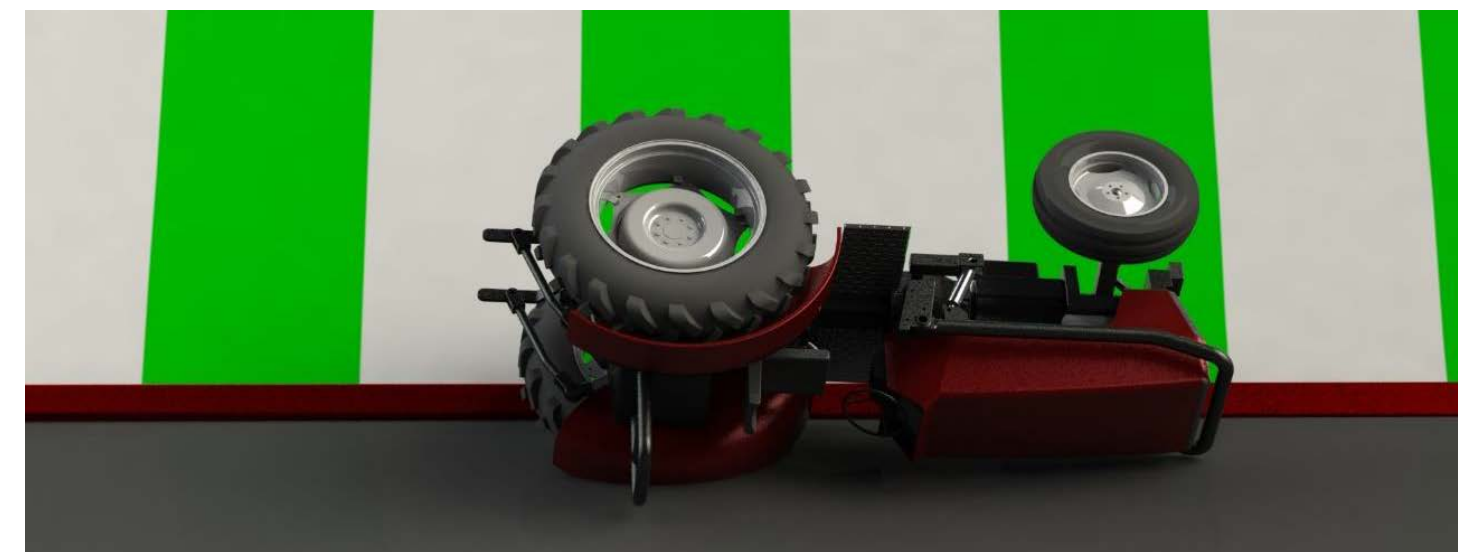

Figure 5. Last frame of the simulation scenario of overturning with ROPS down.

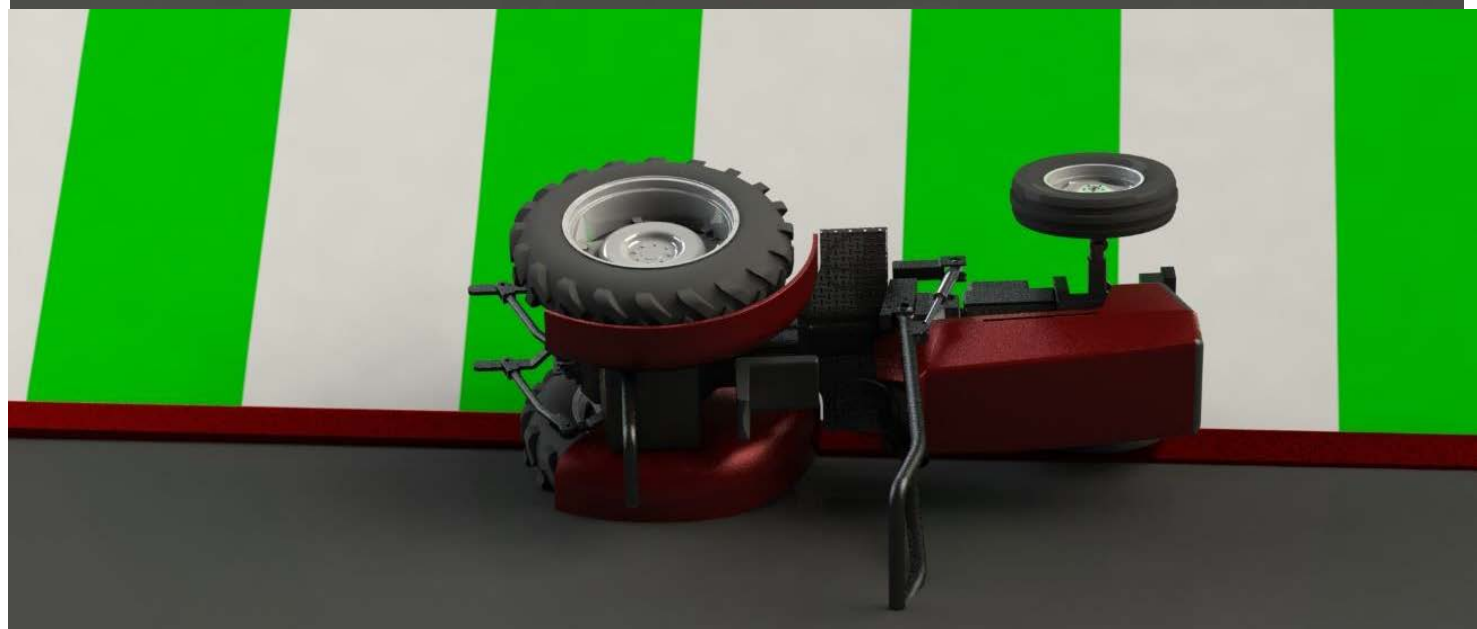

Figure 6. Last frame of the simulation scenario of overturning with ROPS deployed.

\subsection{Lateral rollover experimental results}

Table 2 shows the lateral rollover experimental results with scale tractor in stationary conditions and moving at constant velocity. The test in stationary conditions was not possible to simulate due to restrictions in the software. In all the tests the deployment of ROPS began before the beginning of the rollover, which ensured the safety of the ROPS system. The rollover time in the experimental test is longer than in the dynamic simulation (Table 1 and Table 2). However, the rollover time was longer than the ROPS deployment time (data not shown).

Table 2. Results of lateral rollover tests with scale tractor.

\begin{tabular}{lcccc}
\hline \multirow{2}{*}{ Items } & \multicolumn{5}{c}{ Test } \\
\cline { 2 - 5 } & A & B & C & D \\
\hline Speed of scale tractor 1:16 (km/h) & 0 & 1.42 & 1.88 & 2.53 \\
Real speed (km/h) & 0 & 22.65 & 30.01 & 40.50 \\
Deployment of the ROPS (degrees) & - & 40.5 & 41.7 & 42.7 \\
Starting angle of rollover (degrees) & 44.3 & 44.67 & 44.33 & 44.33 \\
Rollover time (s)* & -- & 0.56 & 0.54 & 0.69 \\
\hline
\end{tabular}

*Maximum of three tests.

\subsection{Comparison of experimental rollover data and dynamic simulation model output}

Table 2 shows the relative errors between the simulated and calculated values at 22.65, 30.01 and $40.50 \mathrm{~km} / \mathrm{h}$. The rollover time in the experimental test is longer than in the dynamic simulation. The maximum relative error was $-17.67 \%$ when the speed was $30.01 \mathrm{~km} / \mathrm{h}$. 


\begin{tabular}{lccc}
\hline \multirow{2}{*}{ Items } & \multicolumn{3}{c}{ Relative errors (\%) } \\
\cline { 2 - 4 } & B & C & D \\
\hline Real speed (km/h) & 3.46 & -1.31 & -2.53 \\
Starting angle of rollover (degrees) & 0.75 & 0.38 & -3.01 \\
Rollover time (s) & -7.17 & -17.67 & -7.14 \\
\hline
\end{tabular}

Tractor stability depends upon many factors. Kelly and Rehkugler (1980) identified 21 variables that may affect the stability of a tractor. These variables were classified into five categories (Kim et al., 1987): static and dynamic tractor properties, initial conditions, driver-controlled parameters, and terrain conditions. In lateral stability analysis, it is important to identify the tipping axis. The tipping axis depends upon the construction of the front wheel and axle assembly. When the tipping axis is designated, the lateral stability can be determined by assuming moments about that axis. The only difference between a static and dynamic analysis is that the latter includes the inertial effects (Kim et al., 1987).

For the variable starting angle of rollover, the maximum relative error between the simulated result and experimental data was $-3.01 \%$, when the speed was $30.01 \mathrm{~km} / \mathrm{h}$. Fig. 7 shows the contact force of the left front wheel with the ground surface during a test at $22.65 \mathrm{~km} / \mathrm{h}$. The rollover occurs at $6.4 \mathrm{~s}$ from the beginning of the ramp.

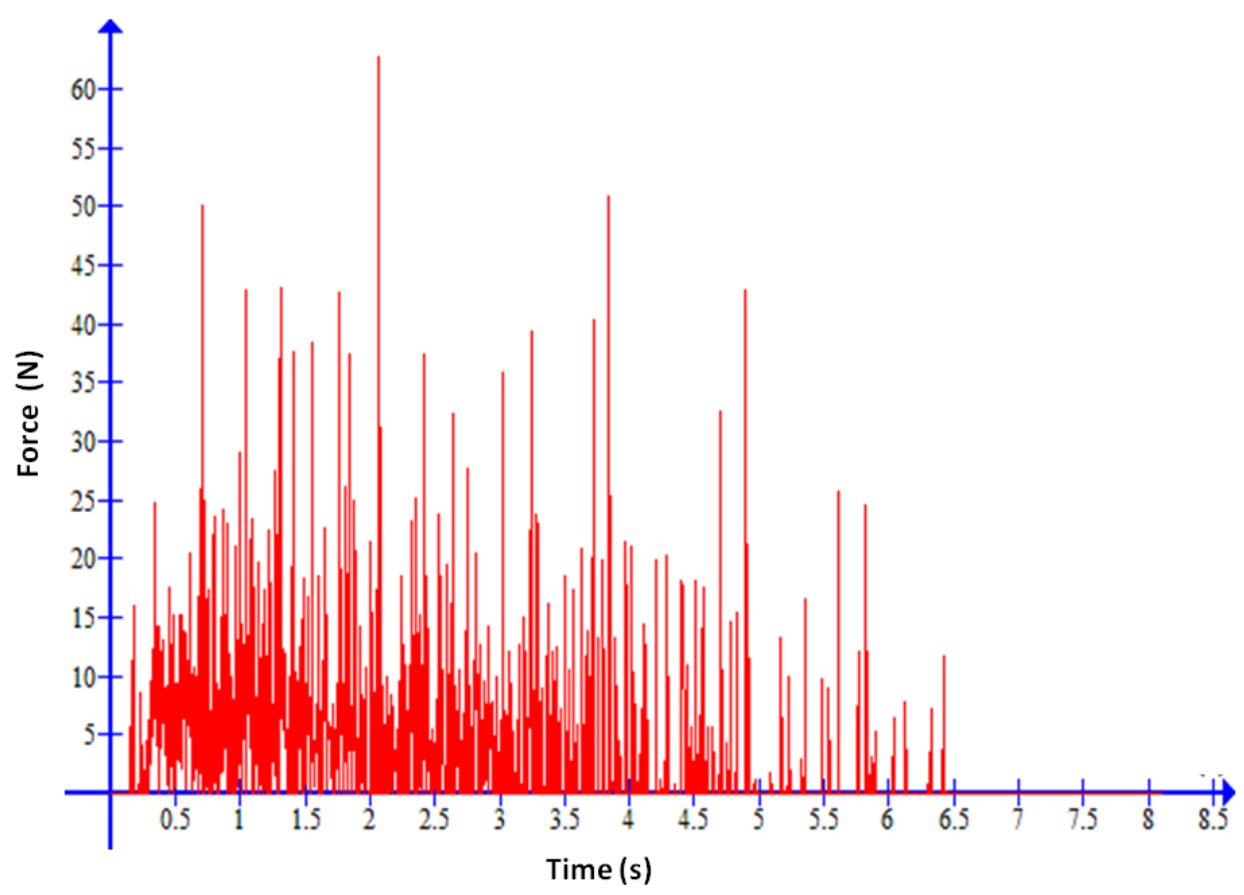

Figure 7. Contact force of the left front wheel with the ground surface during a dynamic simulation test.

\section{Conclusions}

Computer-based dynamic simulation modeling is capable of accurately predicting tractor lateral rollover behavior. For the variable starting angle of rollover, the maximum relative error between the simulated result and experimental data was $-3.01 \%$.

In the simulation scenarios the importance of the ROPS in saving the tractor driver has been highlighted. When the ROPS was down the tractor overturned more than 90 degrees, which would surely in a real situation lead to the death of the driver. However, when the ROPS was deployed, the tractor overturned no more than 90 degrees. $100 \%$ of the fatal accidents were caused by tractor rollover of more than a quarter of a turn.

Speed is a factor that increases the risk of rollover. High speed makes rollover occur with a lower slope and therefore increases the risk of it happening.

\section{Acknowledgements}

The Instituto de Seguridad y Salud Laboral de la Región de Murcia for financing the project of "new safety devices in machinery”. 


\section{References}

Hoy, R. M. (2009). Farm tractor rollover protection: why simply getting rollover protective structures installed on all tractors is not sufficient. J. Agric. Safety Health, 15(1), 3-4.

Kelly, J. E., \& Rehkugler, G. E. (1980). Stability criteria for tractor operation on side slopes. ASAE Special Publication, Engineering a safer machine, p. 145-157. ASAE, St. Joseph, MI 49085.

Kim, K. W., \& Rehkugler, G. E. (1987). A review of tractor dynamics and stability. Trans. ASAE, 30(3), 615-623.

Martin-Gorriz, B., Ibarra Berrocal, I., Mínguez Samper, A., \& Morente Sánchez, A. (2012). Accidentes por vuelco de tractor de la Región de Murcia: propuestas para su reducción. Form. Segur. Lab., 123, 70-71 (in Spanish).

Ojados Gonzalez, D., Martin-Gorriz, B., Ibarra Berrocal, I., Miguel Hernandez, B., Caro Garcia, F., \& Morales Sanchez, P. (2016). Development of an automatically deployable roll over protective structure for agricultural tractors: Prototype and first tests. Comput. Electron. Agric., 124, 46-54.

Scarlett, A. J., Reed, J. N, Semple, D. A., Seward, P. C., Stockton, A. D., \& Price, J. S. (2006). Operator roll-over protection on small vehicles. Silsoe Research Institute. Research report 432. UK: HSE Books.

Silleli, H., Dayıglu, M. A., Gultekin, A., Ekmekci, K., Yildiz, M. A., Akay, E., \& Saranli, G. (2007). Anchor mechanism to increase the operator clearance zone on narrow track wheeled agricultural tractors: prototype and first tests. Biosyst. Eng., 97, 153-161.

Song, A., Huang, B. K., \& Bowen, H. D. (1989). Simulating a powered model wheel-tractor on soft ground. Trans. ASAE, 32(1), 2-11.

Wang, X., Ayers, P., \& Womac, A. R. (2009). Static simulation and analyses of mower's ROPS behavior in a finite element model. J. Agric. Safety Health, 15(4), 335-351. 